\title{
82 Pathology of otosclerosis
}

A Mature lamellar bone is removed and replaced by unorganized woven bone.

B The commonest site is in the posterior promontory in the region of the fossula post fenestram.

C Alpha-1-antitrypsin appears to play a role.

D A type 4 otosclerotic footplate can be scored, fractured and removed.

E Schwartze's sign indicates previous otitis media.

\section{Patients with otosclerosis}

A Are commonly of negroid race.

B May notice an onset or increase of deafness during pregnancy.

C Without a family history may represent new mutations.

D Have a female to male ratio of 2:1.

E First have symptoms between 45 and 55 years in $70 \%$ of cases. 